\title{
A review of hyperspectral remote sensing and its application in vegetation and water resource studies
}

\author{
M Govender ${ }^{1 *}$, K Chetty ${ }^{2}$ and H Bulcock ${ }^{2}$ \\ ${ }^{1}$ CSIR Natural Resources and the Environment, c School of Environmental Sciences, University of KwaZulu-Natal, \\ Private Bag X01, Scottsville 3209, South Africa \\ ${ }^{2}$ School of Bioresources Engineering and Environmental Hydrology, University of KwaZulu-Natal, Private Bag X01, \\ Scottsville 3209, South Africa
}

\begin{abstract}
Multispectral imagery has been used as the data source for water and land observational remote sensing from airborne and satellite systems since the early 1960s. Over the past two decades, advances in sensor technology have made it possible for the collection of several hundred spectral bands. This is commonly referred to as hyperspectral imagery. This review details the differences between multispectral and hyperspectral data; spatial and spectral resolutions and focuses on the application of hyperspectral imagery in water resource studies and, in particular the classification and mapping of land uses and vegetation.
\end{abstract}

Keywords: hyperspectral, multispectral, spectral resolution, spatial resolution, vegetation classification, water resources

\section{Introduction}

Water is one of the most valuable and essential resources that form the basis of all life. With the ever-increasing human population, there is constant stress exerted on water resources (McGwire et al., 2000). Accurate monitoring and assessment of our water resources is necessary for sustained water resource management. Earth observation data have formed the basis for acquiring data remotely for many years (Landgrebe, 1999) and are viewed as a time- and cost-effective way to undertake largescale monitoring (Okin et al., 2001), which can be used to determine the quality, quantity and geographic distribution of this resource.

Multispectral imagery has been used as the data source for water and land observational remote sensing from airborne and satellite systems since the 1960s (Landgrebe, 1999). Multispectral systems commonly collect data in three to six spectral bands in a single observation from the visible and near-infrared region of the electromagnetic spectrum. This crude spectral categorisation of the reflected and emitted energy from the earth is the primary limiting factor of multispectral sensor systems. Over the past two decades, advances in sensor technology have overcome this limitation of earth observation systems, with the development of hyperspectral sensor technologies. Hyperspectral systems have made it possible for the collection of several hundred spectral bands in a single acquisition, thus producing many more detailed spectral data. However, with the advances in hyperspectral technologies practical issues related to increased sensor or imager costs, data volumes and data-processing costs and times would need to be considered especially for operational modes.

\footnotetext{
* To whom all correspondence should be addressed.

용 +27 33260 5276; fax: +27 33260 5266;

e-mail: MGovender@csir.co.za

Received 24 August 2006; accepted in revised form 24 November 2006.
}

This review details the differences between multispectral and hyperspectral data, highlights commonly used remote sensing terminology, and focuses on the use of hyperspectral imagery in water resource studies and, in particular vegetation applications.

\section{Differences between multispectral and hyper- spectral data}

Multispectral airborne and satellite systems have been employed for gathering data in the fields of agriculture and food production, geology, oil and mineral exploration, geography and urban to non-urban localities (Landgrebe, 1999). The advantage of using satellite remote sensing systems was to provide both the synoptic view space provides and the economies of scale, since data over large areas could be gathered quickly and economically from such platforms (Landgrebe, 1999).

Multispectral remote sensing systems use parallel sensor arrays that detect radiation in a small number of broad wavelength bands. According to Smith (2001a), most multispectral satellite systems measure between three and six spectral bands within the visible to middle infrared region of the electromagnetic spectrum. There are, however, some systems that use one or more thermal infrared bands. Multispectral remote sensing allows for the discrimination of different types of vegetation, rocks and soils, clear and turbid water, and selected man-made materials (Smith, 2001a). To obtain data of a higher spectral resolution compared to multispectral data, hyperspectral sensors on board satellites or airborne hyperspectral imagers are used (Smith, 2001b).

Hyperspectral remote sensing imagers acquire many, very narrow, contiguous spectral bands throughout the visible, nearinfrared, mid-infrared, and thermal infrared portions of the electromagnetic spectrum. Hyperspectral sensors typically collect 200 or more bands enabling the construction of an almost continuous reflectance spectrum for every pixel in the scene. Contiguous, narrow bandwidths characteristic of hyperspectral 
data allow for in-depth examination of earth surface features which would otherwise be 'lost' within the relatively coarse bandwidths acquired with multispectral scanners.

Over the past decade, extensive research and development has been carried out in the field of hyperspectral remote sensing. Now with commercial airborne hyperspectral imagers such as CASI and Hymap and the launch of satellite-based sensors such as Hyperion, hyperspectral imaging is fast moving into the mainstream of remote sensing and applied remote sensing research studies. Hyperspectral images have found many applications in water resource management, agriculture and environmental monitoring (Smith, 2001a). It is important to remember that there is not necessarily a difference in spatial resolution between hyperspectral and multispectral data but rather in their spectral resolutions.

\section{Fundamentals of image resolution}

Remotely sensed images are characterised by their spatial and spectral resolutions. The terms spatial and spectral resolution represent pixels of an image displayed in a geometric relationship to one another; and variations within pixels as a function of wavelength respectively. These fundamentals of image resolution are explained below.

\section{Spectral resolution}

Spectral resolution refers to the number and width of the portions of the electromagnetic spectrum measured by the sensor. A sensor may be sensitive to a large portion of the electromagnetic spectrum but have poor spectral resolution if it captures a small number of wide bands. A sensor that is sensitive to the same portion of the electromagnetic spectrum but captures many small bands within that portion would have greater spectral resolution. The objective of finer spectral sampling is to enable the analyst, human or computer, to distinguish between scene elements. Detailed information about how individual elements in a scene reflect or emit electromagnetic energy increases the probability of finding unique characteristics for a given element which allows for better distinction from other elements in the scene (Jensen, 1996). Multispectral remote sensing systems record energy over several separate wavelength ranges at various spectral resolutions. Hyperspectral sensors, detect hundreds of very narrow spectral bands throughout the visible, near-infrared, and mid-infrared portions of the electromagnetic spectrum. A distinct advantage of their very high spectral resolution facilitates fine discrimination between different targets based on their spectral response in each of the narrow bands (Landgrebe, 1999).

\section{Spatial resolution}

Spatial resolution defines the level of spatial detail depicted in an image. This may be described as a measure of the smallness of objects on the ground that may be distinguished as separate entities in the image, with the smallest object necessarily being larger than a single pixel. In this sense, spatial resolution is directly related to image pixel size. The spatial property of an image is a function of the design of the sensor in terms of its field of view and the altitude at which it operates above the surface (Smith, 2001b). Each of the detectors in a remote sensor measures the energy received from a finite patch on the ground surface. The smaller the individual patches are, the higher the spatial resolution and the more detail one can spatially interpret from the image (Smith, 2001b). Currently hyperspectral imagery acquired with satellite systems are usually in the order of $30 \mathrm{~m}$ or finer whereas airborne systems generally acquire higher spatial resolution data usually in the order of $5 \mathrm{~m}$ or finer.

\section{Contiguous spectral signatures}

An understanding of spectral signatures is essential in the understanding and interpretation of a remotely sensed image. Different materials are discriminated by wavelength-dependent absorptions, and these images of reflected solar energy are known as spectral signatures. The property that is used to quantify these spectral signatures is called spectral reflectance. This is a ratio of the reflected energy to incident energy as a function of wavelength (Smith, 2001b). The graph of the spectral reflectance of an object as a function of wavelength is termed the spectral reflectance curve (Lillesand and Kiefer, 1999).

The configuration of the spectral reflectance curves is important in the determination of the wavelength region(s) in which remote sensing data is acquired as the spectral reflectance curves give insight into the spectral characteristics of an object (Lillesand and Kiefer, 1999). Spectral signatures obtained from multispectral images are discrete compared to the contiguous signatures obtained from hyperspectral images. Contiguous spectral signatures allow for detailed analysis through the detection of surface materials and their abundances, as well as inferences of biological and chemical processes.

The three basic contiguous spectral reflectance signatures of earth features used are those for green vegetation, dry bare soil and clear water. Figure 1 shows the average reflectance curves for each feature.

In green vegetation, the valleys in the visible portion of the spectrum are determined by the pigmentation of the plant. For example, chlorophyll absorbs strongly in the blue $(450 \mathrm{~nm})$ and red $(670 \mathrm{~nm})$ regions, also known as the chlorophyll absorption bands. Chlorophyll is the primary photosynthetic pigment in green plants (Smith, 2000b). This is the reason for the human eye perceiving healthy vegetation as green, due to the strong absorption of the red and blue wavelengths and the reflection of the green wavelengths. When the plant is subjected to stress that hinders normal growth and chlorophyll production, there is less adsorption in the red and blue regions and the amount of reflection in the red waveband increases (Smith, 2000b).

The spectral reflectance signature illustrates a dramatic increase in the reflection for healthy vegetation at around

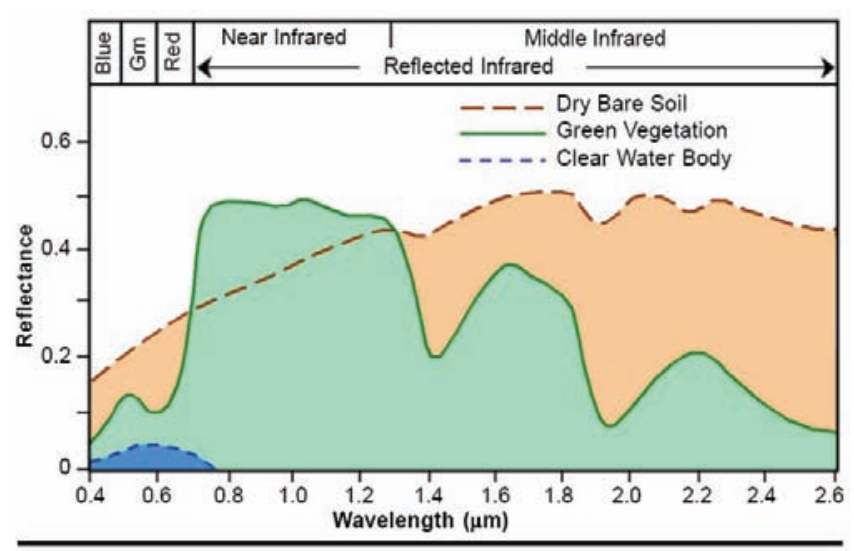

Figure 1

Spectral signatures for dry bare soil, green vegetation and clear water (Smith, 2000b) 
$700 \mathrm{~nm}$. In the NIR between 700 and $1300 \mathrm{~nm}$, a plant leaf will typically reflect between 40 to $50 \%$, the rest is transmitted, with only about $5 \%$ being adsorbed. Structural variability in leaves in this range allows one to differentiate between species, even though they might look the same in the visible region (Lillesand and Kiefer, 1999). Beyond $1300 \mathrm{~nm}$ the incident energy upon the vegetation is largely absorbed or reflected with very little transmittance of energy. Three strong water absorption bands are noted at 1400,1900 and $2700 \mathrm{~nm}$.

The spectral curve for bare soil shows far less variation in reflectance compared to that of green vegetation. This is due to the factors that affect soil reflectance acting over less specific spectral bands. Factors that affect soil reflectance include moisture content, soil texture, surface roughness, presence of iron oxide, and organic matter content. The factors that influence soil reflectance are complex, variable and interrelated (Lillesand and Kiefer, 1999).

The most distinctive characteristic of water is the absorption in the NIR and beyond. There are various conditions of water bodies that manifest themselves in the visible wavelengths. There are complex energy-matter interactions at these wavelengths that depend on a number of factors. These factors include the interaction with the water surface and material suspended in the water. Clear water reflects the greatest at $600 \mathrm{~nm}$. The presence of organic and inorganic materials greatly influences the transmittance of the water and therefore the reflectance is dramatically affected. For example, a water body with high amounts of suspended sediments will reflect better than 'clear' water. An increase in chlorophyll will decrease the reflectance in the blue wavelengths and increase in the green. This can be useful in the detection of algae in water using remote sensing (Lillesand and Kiefer, 1999).

\section{Applications of hyperspectral remote sensing in water resources}

Remote sensing technology has been widely used in water resource applications (Gitelson and Merzlyak, 1996; Zagolski et al., 1996; Asner, 1998; McGwire et al., 2000; Stone et al., 2001; Coops et al., 2002; Underwood et al., 2003) and in particular hyperspectral remote sensing is emerging as the more in-depth means of investigating spatial, spectral and temporal variations in order to derive more accurate estimates of information required for water resource applications. This section briefly highlights applications of hyperspectral remote sensing in water resources, and is followed by a detailed review of the methods and applications of land- use and vegetation classification.

Flood detection and monitoring are constrained by the inability to obtain timely information of water conditions from ground measurements and airborne observations at sufficient temporal and spatial resolutions. Satellite remote sensing allows for timely investigation of areas of large regional extent and provides frequent imaging of the region of interest (Felipe et al., 2006). Until recently, near real-time flood detection was not possible, but with sensors such as Hyperion on board the EO1 satellite this has been vastly improved (Felipe et al., 2006). According to research conducted by Felipe et al. (2006) automated spacecraft technology reduced the time to detect and react to flood events to a few hours. Advances in remote sensing, have resulted in the investigation of early warning systems with potential global applications. Most recent studies from NASA and the US Geological Survey are utilising satellite observations of rainfall, rivers and surface topography into early warning sys- tems (Brakenridge et al., 2006). Specifically, scientists are now employing satellite microwave sensors to gauge discharge from rivers by measuring changes in river widths and satellite based estimates of rainfall to improve warning sytems (Brakenridge et al., 2006). Procedure for the detection of flooded areas with satellite data were also investigated by Glaber and Reinartz (2002). Moisture classes in flood plain areas in relation to high water changes, the accumulation of sediments and silts for different land-use classes and erosive impacts of floods were investigated (Glaber and Reinartz, 2002). The estimation of discharge and flood hydrographs from hydraulic information obtained from remotely sensed data was assessed by Roux and Dartus (2006). Remote sensed images as used to estimate the hydraulic characteristics which are then applied in routing modules to generate a flood wave in a synthetic river channel. Optimisation methods are used to minimise discrepancies between simulations and observations of flood extent fields to estimate river discharge (Roux and Dartus, 2006).

Detection of water quality conditions and parameters is one of the major advantages of hyperspectral remote sensing technologies. Hyperspectral reflectance has been widely used to assess water quality conditions of many open water aquatic ecosystems. This includes classifying the trophic status of lakes (Koponen et al., 2002; Thiemann and Kaufmann, 2002) and estuaries (Froidefond et al., 2002) characterising algal blooms (Stumpf, 2001) and assessment of ammonia dynamics for wetland treatments (Tilley et al., 2003). Predictors of total ammonia concentrations using remotely sensed hyperspectral signatures of macrophytes in order to monitor changes in wetland water quality were developed by Tilley et al. (2003). Hyperspectral spectrometers have also proved useful in determining the total suspended matter, chlorophyll content (Hakvoort et al., 2002; Vos et al., 2003) and total phosphorus (Koponen et al., 2002). Much research has been undertaken in the estimation of chlorophyll content from remotely sensed images which is then used as an estimate for monitoring algal content and hence water quality. Since wavelengths corresponding with the peak reflectance of blue-green and green algae are close together it is more difficult to differentiate between them. However, hyperspectral imagers allow for improved detection of chlorophyll and hence algae, due to the narrow spectral bands which are acquired between $450 \mathrm{~nm}$ and $600 \mathrm{~nm}$. (Hakvoort et al., 2002). Estimation and mapping of water quality constituents such as concentrations of dissolved organic matter, chlorophyll or total suspended matter from optical remote sensing technologies have proved to be useful and successful and are being investigated for operational use (Hakvoort et al., 2002).

Wetland mapping has gained increased recognition for the ability to improve quality of ecosystems (Schmidt and Skidmore, 2003). Sustainable management of any ecosystem requires, among other information, a thorough understanding of vegetation species distribution. Hyperspectral imagery has been used to remotely delineate wetland areas and classify hydrophytic vegetation characteristics of these ecosystems (Schmidt and Skidmore, 2003; Becker et al., 2005). Research undertaken by Schmidt and Skidmore (2003) promoted the use of high spatial and spectral resolution data for improved mapping of salt marsh vegetation of similar structure. The hyperspectral analysis identified key regions of the electromagnetic spectrum which provided detailed information for discriminating between and identifying different wetland species (Schmidt and Skidmore, 2003). Becker et al. (2005) performed a similar study based on 
coastal wetland plant communities which are spatially complex and heterogeneous. This study also emphasised the importance of hyperspectral imagery for identifying and differentiating vegetation spectral properties from narrow spectral bands focussing on the visible and near-infrared regions (Becker et al., 2005). A number of studies have investigated the potential of providing timely data for mapping and monitoring submerged aquatic vegetation which has been identified as one of the most important aspects of ecosystem restoration and reconstruction (Lin and Liquan, 2006). Such species have been termed ecological engineering species and the quantification of their coverage and spectral reflectance properties is currently being researched (Lin and Liquan, 2006).

Measures of plant physiology and structure such as leaf area index, water content, plant pigment content, canopy architecture and density have been investigated extensively over the past decade (Asner, 1998; Datt, 1998; Ceccato et al., 2001; Gitelson et al., 2002; Champagne et al., 2003; Gupta et al., 2003; Merzlyak et al., 2003; Pu et al., 2003; D’Urso et al., 2004; Schlerf et al., 2005; Stimson et al., 2005; Chun-Jiang et al., 2006) using hyperspectral imagery. These applications investigate the spectral reflectance properties of plants, identifying key spectral wavebands related to specific plant physiological and structural characteristics, hence deriving sensitive vegetation spectral indices for their non-destructive estimation. Remote sensing data have been exploited to estimate canopy characteristics by using empirical approaches based on spectral indices (D’Urso et al., 2004; Schlerf et al., 2005). Analysis of hyperspectral remote sensing data has been carried out to estimate LAI for agricultural crops and forests. Schlerf et al. (2005) investigated several narrow band and broad band vegetation indices in order to explore whether hyperspectral data may improve the estimation of biophysical variables such as LAI, canopy crown and crown volume when compared to multispectral analyses. The spectral and spatia information content of the satellite data was exploited to validate canopy reflectance models such as PROSPECT and SAILH (D'Urso et al., 2004). Results obtained for the crops under investigation encourage the use of canopy reflectance models in the inverse mode in order to retrieve other vegetation parameters such as chlorophyll content, dry matter and canopy geometrical characteristics like mean leaf inclination angle (D’Urso et al., 2004). The accurate estimation of plant water status and plant water stress is essential to the integration of remote sensing into precision agricultural and forestry management. The potential to spectrally estimate plant physiological properties over relatively large areas, and to predict plant water status and plant water stress was demonstrated by Champagne et al., 2003 for agricultural crops; and Stimson et al., 2005 and Eitel al., 2006 for forestry species. Their results indicate the potential use of vegetation spectral indices derived from various scales of remote sensing data for determining plant physiological properties and characteristics. These studies amongst others clearly indicate the improved estimates of plant physiological and structural characteristics from hyperspectral data, allowing for much more detailed spectral analyses and hence more accurate estimates.

Evapotranspiration (ET) estimates are essential in a wide range of water resource applications such as water and energy balance computations, in irrigation schemes, reservoir water losses, runoff prediction, meteorology and climatology (Medina et al., 1998). ET cannot be estimated directly from satellite observations; however, hyperspectral remote sensing can provide a good estimate of components of energy balance algorithms used to derive spatial estimates of ET. Earlier studies have focused on the estimation of evaporative fraction (EF) rather than on ET as the estimation of available radiant energy was difficult to obtain. According to Batra et al (2006) an estimation of EF is defined as a ratio of ET and available radiant energy and has been estimated successfully using AVHRR and MODIS data. Several recent studies (Medina et al. 1998; Kite and Droogers, 2000; Loukas et al. 2005; Batra et al. 2006; Eichinger, et al. 2006) have been conducted using more detailed hyperspectral data, ancillary surface data and atmospheric data for improved spatial estimates of ET. The availability of water, radiant energy and the removal of water vapour away from the surface are the major factors that control ET. However these factors in turn depend on other variables such as soil moisture, land surface temperature, air temperature, and vegetation cover, vapour pressure, and wind speed which may vary between regions, seasons, and time of day. Generally these factors are accounted for by using a combination of remote sensing data, ancillary surface data and atmospheric data for the estimation of ET values (Batra et al., 2006), and has lead to extensive measurements of surface fluxes, meteorological and soil variables (Wang et al., 2006). Batra et al (2006) successfully estimated ET based on the extension of the Priestly-Taylor equation and the relationship between remotely sensed surface temperature and vegetation spectral indices.

\section{Land-use and vegetation classification}

Land-use and vegetation classification is generally performed using supervised and unsupervised classification methods which are commonly available in most data processing systems. The key difference in the two methods lies in the training stage of supervised classification which involves identifying areas of specific spectral attributes for each land-cover or land-use type of interest to the analyst. In comparison unsupervised image classification into spectral classes is based solely on the natural groupings from the image values. Furthermore, remote sensing applications and specifically land-use or vegetation classification is seldom done without some form of ground truthing or collection of reference data. Ground-based spectral measurements are commonly done using portable, field spectrometers. Field spectrometers are utilised in forestry, agriculture and other environmental studies; and the spectral signatures obtained can be used in classification and mapping of vegetation, mapping of ecosystem productivity, crop type or yield mapping, and in the detection of plant stress for water resource operations and management.

\section{Applications}

Traditional methods for landscape-scale vegetation mapping require expensive, time-intensive field surveys. Remotely sensed data for the classification and mapping of vegetation provide a detailed accurate product in a time- and cost-effective manner. The availability of satellite and airborne hyperspectral data with its increased spatial and more critically fine spectral resolution offers an enhanced potential for the classification and mapping of land use and vegetation. Due to the large number of wavebands, image processing is able to capitalise on both the biochemical and structural properties of vegetation (Underwood et al., 2003). The need for exploring these spectral properties is particularly important when we consider the limitations of using traditionally available wavebands, where most of the land cover is grouped and identification of individual species is difficult. 
Figure 2

Reflectance spectra of different types of green vegetation compared to a spectral signature for senescent leaves (Smith, 2001a)

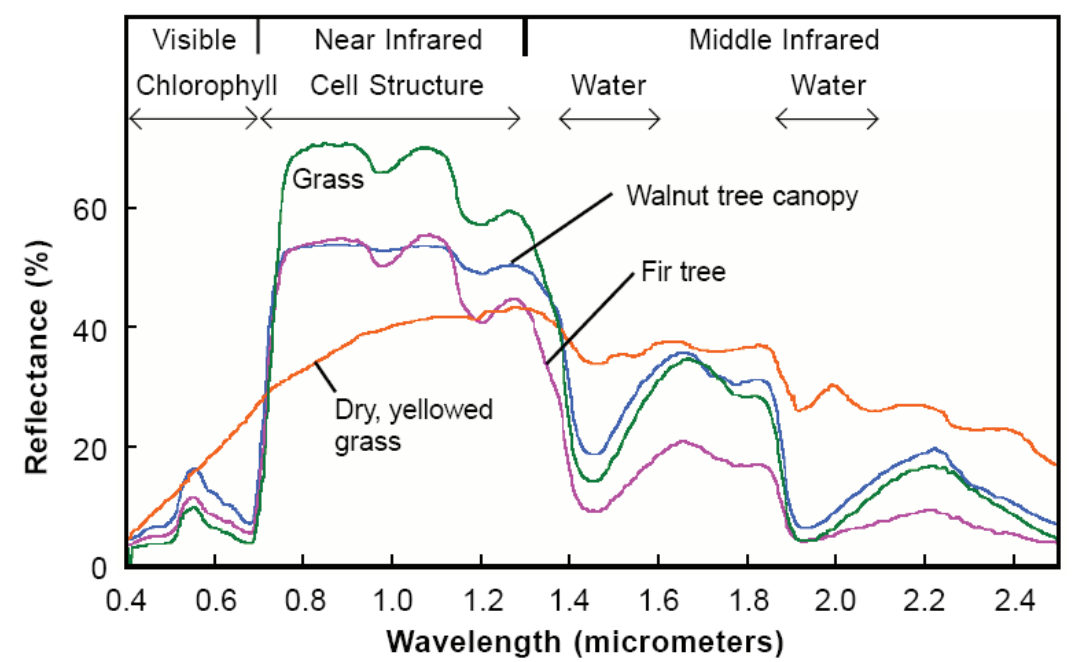

pixel. However, increased information provided by the spatial extent of the classes of the neighbours tends to mitigate the effects of noise, isolated pixels, and individual pixels (CastroEsau, 2004).

Spectral angle mapper classifies by comparing the spectral angles between the reflectance spectrum of the classified pixel and the reference spectrum obtained from training data or a spectral library. Each pixel is assigned to a class according to the lowest spectral angle value (Kruce et al., 1993).

Parallelepiped classification is a decision rule method based on the standard deviation from the mean of each defined and trained class. A threshold of each class signature is used to determine if a given pixel falls within a class. Pixels which fall inside the parallelepiped are assigned to the class; however, those within more than one class are grouped into an overlap class. Pixels ungrouped are considered as unclassified (Lillesand and Kiefer, 1999).

\section{Discussion and conclusion}

Recent advances in remote sensing have led the way for the development of hyperspectral sensors and the application of hyperspectral data. Hyperspectral remote sensing is a relatively new technology to South Africa that is being used in the detection and identification of minerals, terrestrial vegetation, and man-made materials as well as in the field of water resources and environmental applications (Nagy and Jung, 2005).

The availability of hyperspectral data has overcome the constraints and limitations of low spectral and spatial resolution imagery, and discreet spectral signatures. Hyperspectral images provide high spectral resolution data, with many narrow contiguous spectral bands allowing for detailed applications.

This review highlights the vast extent to which hyperspectral technologies have been applied to the water resource and environmental sectors. In particular, the remotely sensed classification and mapping of land use and vegetation has been adopted internationally, since traditional methods of classifying and mapping land use and vegetation require expensive, timeintensive field surveys. Remotely sensed data allow for the classification and mapping of vegetation in a time and cost-effective manner.

Different processing and statistical techniques such as spectral vegetation indices and principal component analysis are often used as data enhancement methods to mask 
vegetated areas within remotely sensed images. Vegetated areas are then classified using one or more recognised classification algorithms such as spectral angle mapper, Gaussian maximum likelihood and parallelepiped, resulting in more accurate products borne from hyperspectral data sources. As hyperspectral imaging techniques evolve and are introduced into new fields their primary contribution will be in exploring and developing new applications primarily on the selection of optimal spectral band parameters i.e. band position and widths. Practical issues of sensor costs, data volumes and data processing mechanisms will need to addressed for operational use, and thus still favour multispectral systems.

In general this review illustrates the enhanced capability of hyperspectral technologies in vegetation and water resource studies and, allows water resource managers to make informed management decisions with the relevant detail in an efficient timeframe.

\section{References}

ASNER GP (1998) Biophysical and biochemical sources of variability in canopy reflectance. Remote Sens. Environ. 64 234-253.

BATRA N, ISLAM S, VENTURINI V, BISHT G and JIANG L (2006) Estimation of comparison of evapotranspiration from MODIS and AVHRR sensors for clear sky days over the Southern Great Plains. Remote Sens. Environ. 103 1-15.

BECKER BL, LUSCH DP and QI J (2005) Identifying optimal spectral bands from in-situ measurements of Great Lakes coastal wetlands using second derivative analysis. Remote Sens. Environ. 97238 248.

BRACKENRIDGE R, ANDERSON E and NGHIEM SV (2006) Satellite microwave detection and measurement of river floods. NASA Spring Annual General Conference 2006. www.nasa.gov/vision/ earth/lookingatearth/springagu 2006.html (Accessed 4 October 2006).

CASTRO-ESAU KL, SANCHEZ-AZOFEIFA GA and CAELLI T (2004) Discrimination of lianas and trees with leaf level hyperspectral data. Remote Sens. Environ. 90 353-372.

CECCATO P, FLASSE S, TARANTOLA S, JACQUEMOUD $S$ and GREGOIRE JM (2001) Detecting vegetation leaf water content using reflectance in the optical domain. Remote Sens. Environ. 77 22-33.

CHAMPAGNE CM, STAENZ K, BANNARI A, MCNAIRN H and DEGUISE JC (2003) Validation of a hyperspectral curve fitting model for the estimation of water content of agricultural canopies. Remote Sens. Environ. 87 148-160.

CHUN-JIANG Z, JI-HUA W, LIANG-YUN L, WEN-JIANG H and QI-FA Z (2006) Relationship of 2100-2300nm spectral characteristics of wheat canopy to leaf area index and leaf $\mathrm{N}$ as affected by leaf water content. Pedosphere 16 333-338.

COOPS N, DURY S, SMITH ML, MARTIN M and OLLINGER S (2002) Comparison of green leaf eucalypt spectra using spectral decomposition. Austral. J. Bot. 50 567-576.

DATT B (1998) Remote sensing of chlorophyll a, chlorophyll b, chlorophyll a+b, and total carotenoid content in eucalyptus leaves. Remote Sens. Environ 66 111-121.

D'URSO GD, DINI L, VUOLO F, ALONSO L and GUANTER L (2004) Retrieval of leaf area index by inverting hyperspectral multiangular CHRIS PROBA data from SPARC 2003. Proc. $2^{\text {nd }}$ CHRIS Proba Workshop. 28 to 30 April, ESA/ESRIN, Frascati Italy.

FELIPE IP, DOHM JM, BAKER VR, DOGGETT T, DAVIES AG, CASTANO R, CHIEN S, CICHY B, GREELEY R, SHERWOOD R, TRAN D, RABIDEAU G (2006) Flood detection and monitoring with the autonomous sciencecraft experiment onboard EO-1. Remote Sens. Environ. 101 463-481.

EICHINGER WE, COOPER DI, HIPPS LE, KUSTAS WP, NEALE CMU and PRUEGER JH (2006) Spatial and temporal variation in evapotranspiration using Raman Lidar. Adv. Water Resour. 29 369381.
FROIDEFOND J, GARDEL L, GUIRAL D, PARRA M and TERNON $J$ (2002) Spectral remote sensing reflectances of coastal waters in French Guiana under the Amazon influence. Remote Sens. Environ. 80 225-232.

GALVAO LS, FORMAGGIO, AR and TISOT DA (2005) Discrimination of sugarcane varieties in South Eastern Brazil with EO-1 Hyperion data. Remote Sens. Environ. 94 523-534.

GITELSON AA and MERZLYAK MN (1996) Signature analysis of leaf reflectance spectra: algorithm development for remote sensing of chlorophyll. J. Plant Physiol. 148 494-500.

GITELSON AA, ZUR Y, CHIVKUNOVA, OB and MERZLYAK MN (2002) Assesing carotenoid content in plant leaves with reflectance spectroscopy. Photochem. Photobiol. 75 272-281.

GLABER C and REINARTZ, P (2004) Multitemporal and multispectral remote sensing approach for flood detection in the Elbe-Mulde region 2002. Acta Hydrochim. Hydrobiol. 33 (5).

GUPTA RK, VIJAYAN D and PRASAD TS (2003) Comparative analysis of red-edge hyperspectral indices. Adv. Space Res. 32 22172222.

HAKVOORT H, DE HAAN J, JORDANS R, VOS R, PETERS S and RIJKEBOER M (2002) Towards airborne remote sensing of water quality in the Netherlands-validation and error analysis. J. Photogr. Remote Sens. 57 171-183.

JENSEN, JR (1996) Introductory Digital Image Processing: A Remote Sensing Perspective. Prentice-Hall, New Jersey.

KITE G and DROOGERS P (2000) Comparing evapotranspiration estimates from satellites, hydrological models and field data. J. Hydrol. 229 3-18.

KOCH M, INZANA J and EL BAZ F (2005) Applications of hyperion hyperspectral and aster multispectral data in characterizing vegetation for water resource studies in arid lands. Geol. Remote Sens. 16 to 19 October 2005, Salt Lake City Annual Meeting. Paper No. 44-5.

KOPONEN S, PULLIAINEN J, KALLIO K and HALLIKAINEN M (2002) Lake water quality classification with airborne hyperspectral spectrometer and simulated MERIS data. Remote Sens. Environ. 79 51-59.

KRUCE F, LEFKOFF A, BOARDMAN J, HEIDEBRECHT K, SHAPIRO A, BARLOON P and GOETZ A (1993) The spectral image processing system (SIPS) interactive visualization and analysis of imaging spectrometer data. Remote Sens. Environ. 44 145-163.

LANDGREBE D (1999) On information extraction principles for hyperspectral data. Cybernetics 28 part c, 1, 1-7.

LANDGREBE D (1999) Some fundamentals and methods for hyperspectral image data analysis. Systems and Technologies for Clinical Diagnostics and Drug Discovery II, 3603. 6 pp.

LILLESAND TM and KIEFER RW (1999) Remote Sensing and Image Interpretation. John Wiley \& Sons, Inc. New Jersey.

LIN Y and LIQUAN Z (2006) Identification of the spectral characteristics of submerged plant Vallisneria spiralis. Acta Ecol. Sin. 26 10051011.

LOUKAS A, VASILIADES L, DOMENIKIOTIS C and DALEZIOS NR (2005) Basin wide actual evapotranspiration using NOAA/ AVHRR satellite data. Phys. Chem. Earth 30 69-79.

MCGWIRE K, MINOR T and FENSTERMAKER L (2000) Hyperspectral mixture modeling for quantifying sparse vegetation cover in arid environments. Remote Sens. Environ. 72 360-374.

MEDINA JL, CAMACHO E, RECA J, LOPEZ R and ROLDAN J (1998) Determination and analysis of regional evapotranspiration in Spain based on remote sensing and GIS. Phys. Chem. Earth 23 427-432.

MERZLYAK MN, SOLOVCHENKO AE and GITELSON, AA (2003) Reflectance spectral features and non-destructive estimation of chlorophyll, carotenoid and anthocyanin content in apple fruit. Postharvest Biol. Technol. 27 197-211.

NAGY Z and JUNG A (2005) A case study of the anthropogenic impact on the catchment of Mogyorod-brook, Hungary. Phys. Chem. Earth 30 588-597.

OKIN GS, ROBERTS DA, MURRAY B, OKIN WJ (2001) Practical limits on hyperspectral vegetation discrimination in arid and semiarid environments. Remote Sens. Environ. 77 212-225.

PU R, GE S, KELLY NM and GONG P (2003) Spectral absorption features as indicators of water status in coast live oak leaves. Int. J. Remote Sens. 24 1799-1810. 
ROUX H and DARTUS D (2006) Use of parameter optimization to estimate a flood wave: potential applications to remote sensing of rivers. J. Hydrol. 328 258-266.

SCHLERF M, ATZBERGER C and HILL J (2005) Remote sensing of forest biophysical variables using HyMap imaging spectrometer data.Remote Sens. Environ. 95 177-194.

SCHMIDT KS and SKIDMORE AK (2003) Spectral discrimination of vegetation types in a coastal wetland. Remote Sens. Environ. 85 92-108.

SMITH RB (2001a) Introduction to hyperspectral imaging. www. microimages.com (Accessed 11/03/2006).

SMITH RB (2001b) Introduction to remote sensing of the environment. www.microimages.com (Accessed 24/03/2006).

STIMSON HC, BRESHEARS DD, USTIN SL and KEFAUVER SC (2005) Spectral sensing of foliar water conditions in two co-occurring conifer species: Pinus edulis and Juniperus monosperma. Remote Sens. Environ. 96 108-118.

STONE C, CHISHOLM L and COOPS N (2001) Spectral reflectance characteristics of eucalypt foliage damaged by insects. Aust. J. Bot. 49 687-698.

STUMPF RP (2001) Applications of satellite ocean color sensors for monitoring and predicting harmful algal blooms. Hum. Ecol. Risk Assess. 7 1363-1368.

THIEMANN S and KAUFMANN H (2002) Lake water quality monitoring using hyperspectral airborn data - a semiempirical multisen- sor and multitemporal approach for the Mecklenburg Lake District, Germany. Remote Sens. Environ. 81 228-237.

TILLEY DR, AHMED M, SON, JH and BADRINARAYANAN H (2003) Hyperspectral reflectance of emergent macrophytes as an indicator of water column ammonia in an oligohaline, subtropical marsh. Eco. Eng. 21 153-163.

UNDERWOOD E, USTIN S and DIPIETRO D (2003) Mapping nonnative plants using hyperspectral imagery. Remote Sens. Environ. 86 150-161.

VOS RJ, HAKVOORT JHM, JORDANS, RWJ and IBELINGS BW (2003) Multiplatform optical monitoring of eutrophication in temporally and spatially variable lakes. Sci. Total Environ. 312 221-243.

WANG K, LI Z and CRIBB M (2006) Estimation of evaporative fraction from a combination of day and night land surface temperatures and NDVI: A new method to determine the Priestly-Taylor parameter. Remote Sens. Environ. 102 293-305.

YAMANO H, CHEN J and TAMURA M (2003) Hyperspectral identification of grassland vegetation in Xilinahot, Inner Mongolia, China. Int. J. Remote Sens. 24 3171-3178.

ZAGOLSKI F, PINEL V, ROMIER J, ALCAYDE D, GASTELLUETCHEGORRY JP, GIORDANO G, MARTY G, MOUGIN E and JOFFRE R (1996) Forest canopy chemistry with high spectral resolution remote sensing. Int. J. Remote Sens. 17 1107-1128. 
Available on website http://www.wrc.org.za ISSN 0378-4738 = Water SA Vol. 33 No. 2 April 2007 ISSN 1816-7950 = Water SA (on-line) 